\title{
Effect of Raphanus Sativus (Radish) Leaf Extract on Atorvastatin Induced Hepatotoxicity in Rabbits
}

Obaid Anwar, Mazhar Iqbal, Sadia Chiragh, Owais bin Qadeer Gill, Muhammad Iqbal

\section{ABSTRACT}

Objectives: To investigate hepato-protective effect of ethanolic leave extract of Raphanus sativus against atorvastatin induced hepatotoxicity in albino rabbits.

Study design: Experimental study

Material and Method: This study conducted at department of Physiology and Pharmacology, University of Agriculture, Faisalabad. The ethanolic extract of Raphanus sativus was prepared for hepatoprotective effect against hepatotoxicity produced by atorvastatin.

Results: The results were compared with normal and experimental control. Serum was tested for ALT, AST, Alkaline Phosphatase and Bilirubin along with histological studies. Ethanolic extract of Raphanus sativus with $100 \mathrm{mg} / \mathrm{kg}$. of body weight dosage developed some changes representing hepatotoxicity but higher doses showed an increase in toxicity as observed on histologic sections. A reduction in fibrosis and cholestasis was observed which needs further evaluation.

Conclusion: Ethanolic extract of raphanus sativus did not show any amelioration in the increased enzymes level however a reduction in cholestasis was observed as represented by decreases in alkaline phosphatase levels also confirmed by histological studies.

Key words: ALT, AST, Alkaline phosphatase, Bilirubin, Atorvastatin, Raphanus sativus.

\section{INTRODUCTION:}

Globally traditional medicines are rapidly gaining economic importance. Complementary-alternative and traditional medicine are gaining more and more respect by national governments and health providers in developing countries ${ }^{1}$. About $85 \%$ of world population uses herbal medicines for prevention and treatment of diseases. The demand is increasing in developed and developing countries ${ }^{2}$. A variety of chemical compounds are present in the plant as well as in fruits ${ }^{3}$.

The liver is very important organ for metabolic functions. The liver is involved in wide range of physiological functions, which includes the biochemical pathways to growth, fight against disease, nutrient supply, energy provision and

\begin{tabular}{l} 
Obaid Anwar \\
Department of Pharmacology, \\
I Faisalabad Medical University, Faisalabad \\
Mazhar Iqbal \\
I PHRC, Research Centre, Faisalabad Medical University, I \\
I Eaisalabad \\
I Imail: mazhar.iqbal174@gmail.com \\
I Sadia Chiragh \\
I Postgraduate Medical Institute, \\
I Lahore \\
I Owais bin Qadeer Gill \\
I Fanjab Institute of Nuclear Medicine (PINUM), \\
I Muhammad. \\
I Punjab Institute of Nuclear Medicine (PINUM), \\
I Faisalabad. \\
I Received: 27-7-2018 \\
I Accepted: 26-9-2018 \\
\hline
\end{tabular}

reproduction. Due to these important activities, the liver is exposed to a number of insults and is one of the body's organs most subject to injury ${ }^{4,5}$. Herbal drugs play an important role in the management of different liver disorders most of which fasten the natural healing processes of the liver. Several medicinal plants and their formulations are used for liver disorders in traditional system of medicine from a prolonged period of time . $^{6}$

In developed countries hepatotoxicity caused by various toxicants such as paracetamol, certain chemotherapeutic agents, carbon tetrachloride, thioacetamide, chronic alcohol consumption and microbes is among the major health problems ${ }^{7}$. Statins [competitive inhibitors of 3-hydroxy-3methylglutaryl coenzyme A (HMG-CoA) reductase] are one of the most effective, well tolerated and commonly used drug for treating hyperlipidemia ${ }^{8}$. But myotoxicity and hepatotoxicity are the two main common significant adverse effects of statins especially with high doses ${ }^{9}$. Radishes are grown and consumed throughout the world, being mostly eaten raw as a crunchy salad vegetable but they also have various medicinal actions. Traditionally its leaves, seeds and roots have been in use for several disorders such gastrointestinal, cardiac, biliary, hepatic, urological and respiratory ${ }^{10,11}$. The Objectives of this study are to study the atorvastatin induced hepatotoxicity in albino rabbits and to evaluate the hepatoprotective effects of ethanolic extract of Raphanus sativus leaves against atorvastatin induced hepatotoxicity in albino rabbits.

\section{MATERIAL AND METHODS:}

This 1 year experimental study was carried out in Department of Pharmacology and Therapeutics, Post Graduate Medical 
Institute, Lahore and Department of Physiology and Pharmacology, University of Agriculture, Faisalabad. Pakistan. Ethical approval of the study was taken from Ethical Review Committee (ERC), University of Health sciences, Lahore.

$100 \mathrm{~kg}$ fresh leaves of Raphanus sativus were purchased from local vegetable market and taxonomical identification was carried out at University of Agriculture, Faisalabad, Pakistan (Herbarium voucher no. 173-14-1). Washed leaves were desiccated in shade at room temperature for 10 days, dehydrated with hot air oven at $60^{\circ} \mathrm{C}$ for six hours and then grinded in an electric grinder. The powder obtained was passed through mesh sieve and then extracted with $80 \%$ ethanol and filtered with filter paper (Whatman No. 2). The extracts were concentrated in a hot air oven at $37^{\circ} \mathrm{C}$, lyophilized by freeze drying apparatus (Christ Germany model \# Alpha 1- 4LSC) and subsequently stored in an air tight container in a freezer at $-20^{\circ} \mathrm{C}^{12}$. On daily basis 2,4 and 8 grams of extract was dissolved in $20 \mathrm{ml}$ of distilled water yielding 100, 200 and $400 \mathrm{mg}$ of extract in $1 \mathrm{ml}$ of solution.

99\% pure Atorvastatin was obtained from StandPharm PVT Ltd. Lahore Pakistan. $2 \mathrm{~g}$ of it was dissolved in $100 \mathrm{ml}$ of distilled water yielding $20 \mathrm{mg}$ atorvastatin in $1 \mathrm{ml}$-distilled water for administration. All the reagents used were of analytical grades.

50 adult male rabbits of 6-8 weeks old were purchased from the local market of Faisalabad, Pakistan. The physical examination of the animals was carried out in UAF animal house by veterinary doctor before randomization. The weight of rabbits ranged from $1 \mathrm{~kg}$ to $1.5 \mathrm{~kg}$. They were housed in individual labeled iron cages of appropriate size in the department of Clinical Medicine and Surgery, University of Agriculture, Faisalabad, Pakistan at room temperature. The rabbits were randomly divided into 5 groups with 10 rabbits in each group and labeled as: Group A (Normal control) with routine diet, B (Positive control) with Atorvastatin (20mg/kg b.w.), C (Experimental group I) with Atorvastatin (20mg/kg b.w.) + R. sativus leaf extract (100mg/kg b.w.), D (Experimental group II) with Atorvastatin $20 \mathrm{mg} / \mathrm{kg}+R$. sativus leaf extract $200 \mathrm{mg} / \mathrm{kg}$ b.w. and $\mathbf{E}$ (Experimental group III) Atorvastatin $20 \mathrm{mg} / \mathrm{kg}$ b.w. $+R$. sativus leaf extract $400 \mathrm{mg} / \mathrm{kg}$ b.w. for 28 days. Seasonal fodder and grains were used to fed Rabbits along with water ad libitum. Prior to experimentation, the rabbits were acclimatized for one week. All the rabbits were kept fasting overnight prior to the administration of test extracts.

With a $3 \mathrm{ml}$ disposable syringe 2 blood samples on 0 and 28 day were collected from jugular vein. After 30 minutes blood was centrifuged at $1000 \mathrm{xg}$ for 15-20 min and serum was stored $-20^{\circ} \mathrm{C}$ for biochemical analysis. Animal were sacrificed at day 28 for Liver wt. /body weight ratio and histology.

Serum bilirubin, ALT, AST and Alkaline Phosphatase were determined on chemistry analyzer Vitalab selectra E (Vital scientific, N. V., Netherland) at Allied hospital Faisalabad, Pakistan by using biochemical kits (Human, Germany) as per manufacturer instructions.

All the animals were weighed and sacrificed at end of experiment. The stomach was excised, liver tissue was dissected out and washed with normal saline. The livers were then sectioned into small pieces, fixed with formalin, dehydrated with ethanol, cleared with xylene, infiltered with melted paraffin wax, embedded in wax, sectioned, mounted on slides, stained with $H \& E^{13}$. The slides were finally observed for the pathological changes in liver tissue microscope with a 40X objective.

The data was analyzed using SPSS 20.0. Mean + SE was calculated for quantitative variables, which included $\mathrm{S}$. bilirubin (total, direct and indirect), ALT, AST and alkaline phosphatase. $\mathrm{P}$-value $=0.05$ was considered as statistically significant.

\section{RESULTS:}

Serum bilirubin levels (Total, direct and indirect) were measured on day 0 and 28 . When compared by one way ANOVA, it was observed that all groups were similar on day 0 but significantly different on day 28 as seen in table 1. Serum Alanine Aminotransferase (ALT), Aspartate Aminotrans-ferase (AST) and Alkaline phosphatase levels were measured on day 0 and 28. When compared by one way ANOVA and post hoc tukey's test, it was observed that all groups were similar on day 0 but significantly different on day 28 as shown in Table 2.

Photomicrograph was made from slides obtained from all groups were studied and. Parameter such as degeneration, steatosis, necrosis, triaditis were used for scoring the damage. Damage was graded as nil, mild and moderate and scored as 0,1 and 2 respectively.

Photomicrograph of the liver tissue was obtained from the rabbit treated as normal control. Figure. 1 shows hepatic parenchyma is normal in appearance with central vein, cords of hepatocytes with prominent nuclei and portal tract.

Degeneration was absent in group A and C. Group B had mild to moderate degenerative changes. Group D had higher and group $\mathrm{E}$ had highest degenerative changes. Chi-square test revealed very highly significant difference between groups. Chi-square test revealed very highly significant difference between groups (Table 3 and, fig. 2).

Steatosis was absent in group A, B, C and D. Only two cases in group $\mathrm{E}$ showed changes of steatosis. Chi-square test revealed insignificant difference between groups (Table 4, fig. 3). Necrosis was absent in group A, C, D and E. Only two cases had mild necrosis in group B. Chi-square test revealed insignificant difference between groups (Table 3 , fig.4). Triaditis was absent in group A. Four cases had severe triaditis in group B while rest of them showed mild form of 
Obaid Anwar, Mazhar Iqbal, Sadia Chiragh, Dr. Owais bin Qadeer Gill, Muhammad Iqbal

\begin{tabular}{|l|c|c|c|c|c|c|}
\hline \multirow{2}{*}{ Groups } & \multicolumn{2}{|c|}{ Total } & \multicolumn{2}{c|}{ Direct } & \multicolumn{2}{c|}{ Indirect } \\
\cline { 2 - 7 } & 0 Day & 28 Day & 0 Day & 28 Day & 0 Day & 28 Day \\
\hline A $($ normal) & $0.590+0.035$ & $0.590+0.028$ & $0.220+0.013$ & $0.250+0.017$ & $0.370+0.030$ & $0.340+0.027$ \\
\hline B $($ At. $20 \mathrm{mg} / \mathrm{kg})$ & $0.640+0.04$ & $0.920+0.073$ & $0.230+0.015$ & $0.320+0.029$ & $0.410+0.031$ & $0.600+0.047$ \\
\hline C (At. $20 \mathrm{mg} / \mathrm{kg}+$ R. S. $100 \mathrm{mg} / \mathrm{kg})$ & $0.590+0.046$ & $0.700+0.047$ & $0.220+0.013$ & $0.250+0.017$ & $0.370+0.037$ & $0.450+0.043$ \\
\hline D (At. $20 \mathrm{mg} / \mathrm{kg}+$ R. S.200mg/kg) & $0.600+0.030$ & $0.830+0.042$ & $0.230+0.05$ & $0.330+0.015$ & $0.370+0.021$ & $0.510+0.031$ \\
\hline E $($ At. $20 \mathrm{mg} / \mathrm{kg}+$ R. S.400mg $/ \mathrm{kg})$ & $0.580+0.036$ & $0.930+0.040$ & $0.220+0.013$ & $0.340+0.016$ & $0.370+0.030$ & $0.590+0.031$ \\
\hline ANOVA (P-Value) & $0.816^{\text {NS }}$ & $0.000 * * *$ & $0.962^{\mathrm{NS}}$ & $0.002^{* *}$ & $0.884^{\mathrm{NS}}$ & $0.000^{* * *}$ \\
\hline
\end{tabular}

At: Atorvastatin; R.S.:Raphanus Sativus; NS = Non- significant $(\mathrm{P}>0.05) ; *=$ Significant $(\mathrm{P}<0.05)$; ** $=$ Highly significant $(\mathrm{P}<0.01) ; * * *=$ Very highly significant $(\mathrm{P}<0.001)$

Table 1: Effect of R.sativus extract on serum bilirubin levels (IU/L) of atorvastatin treated rabbits. Data indicates mean + SE values

\begin{tabular}{|l|c|c|c|c|c|c|}
\hline \multirow{2}{*}{ Groups } & \multicolumn{2}{|c|}{ ALT } & \multicolumn{2}{c|}{ AST } & \multicolumn{2}{c|}{ Al. phosphatase } \\
\cline { 2 - 7 } & 0 Day & 28 Day & 0 Day & 28 Day & 0 Day & 28 Day \\
\hline A $($ normal) & $73.00+5.05$ & $66.70+06.13$ & $81.80+1.88$ & $77.90+03.37$ & $76.20+3.41$ & $78.30+3.61$ \\
\hline B (At. $20 \mathrm{mg} / \mathrm{kg})$ & $63.10+5.15$ & $149.40+14.55$ & $79.00+3.96$ & $197.90+13.11$ & $84.00+3.82$ & $117.50+7.94$ \\
\hline C (At. $20 \mathrm{mg} / \mathrm{kg}+$ R. S.100mg/kg) & $65.70+2.11$ & $133.40+06.83$ & $74.60+3.62$ & $154.80+07.72$ & $73.00+5.28$ & $110.80+5.52$ \\
\hline D (At. $20 \mathrm{mg} / \mathrm{kg}+$ R. S.200mg/kg) & $67.80+3.57$ & $174.80+10.54$ & $74.10+4.40$ & $211.60+14.41$ & $80.30+8.93$ & $142.40+7.19$ \\
\hline E (At. $20 \mathrm{mg} / \mathrm{kg}+$ R. S.400mg/kg) & $72.20+4.88$ & $200.60+14.17$ & $73.50+5.38$ & $218.50+14.45$ & $72.00+4.04$ & $127.50+5.14$ \\
\hline ANOVA $($ P-Value) & $0.439^{\mathrm{NS}}$ & $0.000^{* * *}$ & $0.522^{\mathrm{NS}}$ & $0.000^{* *}$ & $0.504^{\mathrm{NS}}$ & $0.000^{* * *}$ \\
\hline
\end{tabular}

At: Atorvastatin; R.S.:Raphanus Sativus; NS = Non significant $(\mathrm{P}>0.05) ; *=$ Significant $(\mathrm{P}<0.05) ; * *=$ Highly significant $(\mathrm{P}<0.01) ; * *=$ Very highly significant $(\mathrm{P}<0.001)$

Table 2: Effect of R. sativus extract on Alanine aminotransferase (ALT), Aspartate aminotransferase (AST) and Alkaline phosphatase (IU/L) of atorvastatin treated rabbits. Data indicates mean $+\mathrm{SE}(\mathrm{n}=10)$

\begin{tabular}{|c|c|c|c|c|c|c|}
\hline $\begin{array}{l}\text { Histological } \\
\text { parameter }\end{array}$ & $\begin{array}{c}\mathbf{A} \\
\text { (Normal) }\end{array}$ & $\begin{array}{c}\text { B } \\
\text { At. } 20 \mathrm{mg} / \\
\mathrm{kg}\end{array}$ & \begin{tabular}{|c|}
$\mathbf{C}$ \\
At. $20 \mathrm{mg} / \mathrm{kg}+$ \\
$R . S .100 \mathrm{mg} / \mathrm{kg}$
\end{tabular} & $\begin{array}{c}\text { D } \\
\text { At. } 20 \mathrm{mg} / \mathrm{kg}+ \\
R . S .200 \mathrm{mg} / \mathrm{kg}\end{array}$ & $\begin{array}{c}\mathbf{E} \\
\text { At. } 20 \mathrm{mg} / \mathrm{kg}+ \\
R . S .400 \mathrm{mg} / \mathrm{kg}\end{array}$ & Chi-square \\
\hline \multicolumn{7}{|l|}{ Degeneration } \\
\hline $\mathrm{Nil}$ & $10(100)$ & $5(50)$ & $10(100)$ & $4(40)$ & $4(40)$ & \multirow{3}{*}{$29.70 * * *$} \\
\hline Mild & $0(0)$ & $4(40)$ & $0(0)$ & $0(0)$ & $2(20)$ & \\
\hline Moderate & $0(0)$ & $1(10)$ & $0(0)$ & $6(60)$ & $4(40)$ & \\
\hline \multicolumn{7}{|l|}{ Steatosis } \\
\hline Nil & $10(100)$ & $10(100)$ & $10(100)$ & $10(100)$ & $8(80)$ & \multirow{3}{*}{$8.33^{\mathrm{NS}}$} \\
\hline Mild & $0(0)$ & $0(0)$ & $0(0)$ & $0(0)$ & $2(20)$ & \\
\hline Moderate & $0(0)$ & $0(0)$ & $0(0)$ & $0(0)$ & $0(0)$ & \\
\hline \multicolumn{7}{|l|}{ Necrosis } \\
\hline Nil & $10(100)$ & $8(80)$ & $10(100)$ & $10(100)$ & $10(100)$ & \multirow{3}{*}{$8.33^{\mathrm{NS}}$} \\
\hline Mild & $0(0)$ & $2(20)$ & $0(0)$ & $0(0)$ & $0(0)$ & \\
\hline Moderate & $0(0)$ & $0(0)$ & $0(0)$ & $0(0)$ & $0(0)$ & \\
\hline \multicolumn{7}{|l|}{ Triaditis } \\
\hline Nil & $10(100)$ & $0(0)$ & $0(0)$ & $0(0)$ & $0(0)$ & \multirow{3}{*}{$8.67 * * *$} \\
\hline Mild & & $5(50)$ & $10(100)$ & $0(0)$ & $0(0)$ & \\
\hline Moderate & & $5(50)$ & $0(0)$ & $10(100)$ & $10(100)$ & \\
\hline
\end{tabular}

Table 3: Effect of Raphanus sativus extract on histological changes 


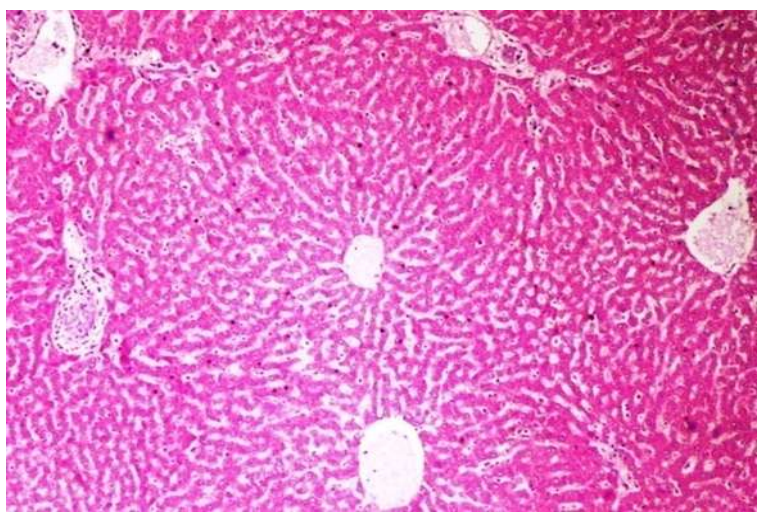

Fig. 1: Photomicrograph of liver showing normal architecture of liver lobule with central vein, cords of hepatocytes with prominent nuclei and portal tract (H\&E stain $\mathrm{x} 10)$

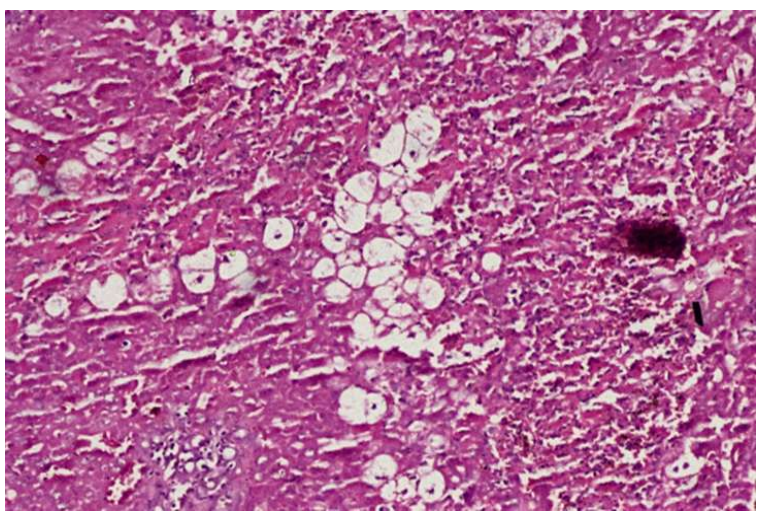

Figure 3: Photomicrograph showing steatosis (H\&E stain $\mathrm{x} 40$ )

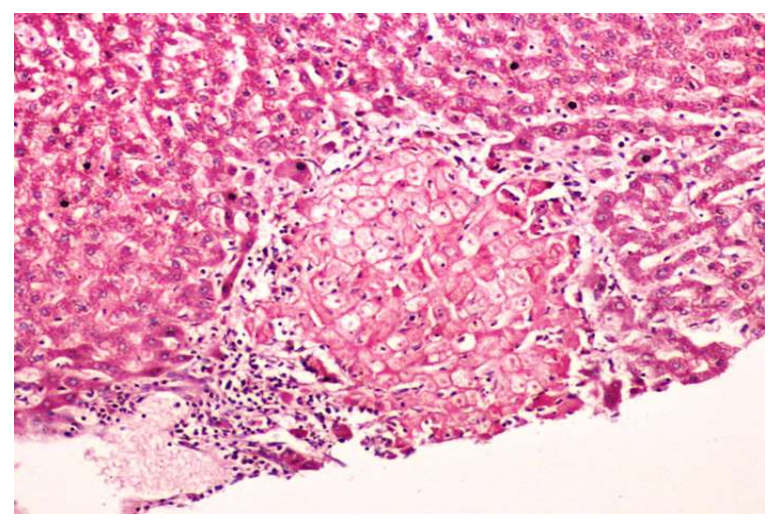

Figure 2: Photomicrograph of liver showing (ballooning) degeneration of liver (H\&E stain $\mathrm{x} 40)$

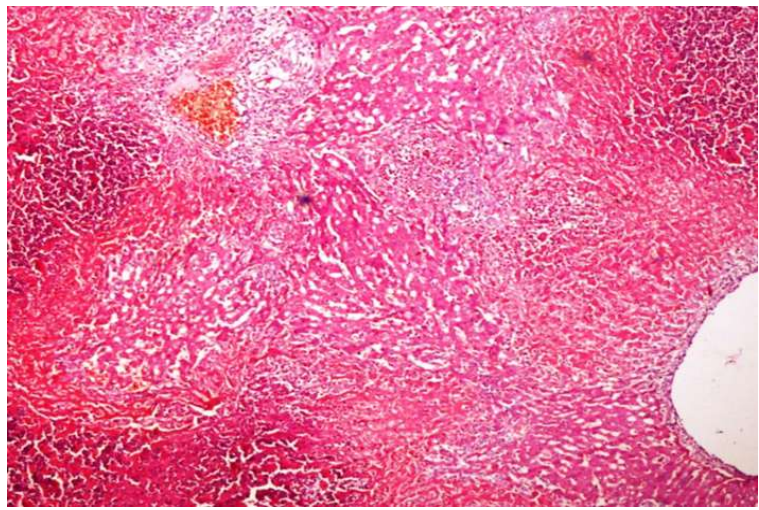

Figure 4: Photomicrograph of liver showing early signs of necrosis (H\&E stain $\mathrm{x} 10)$

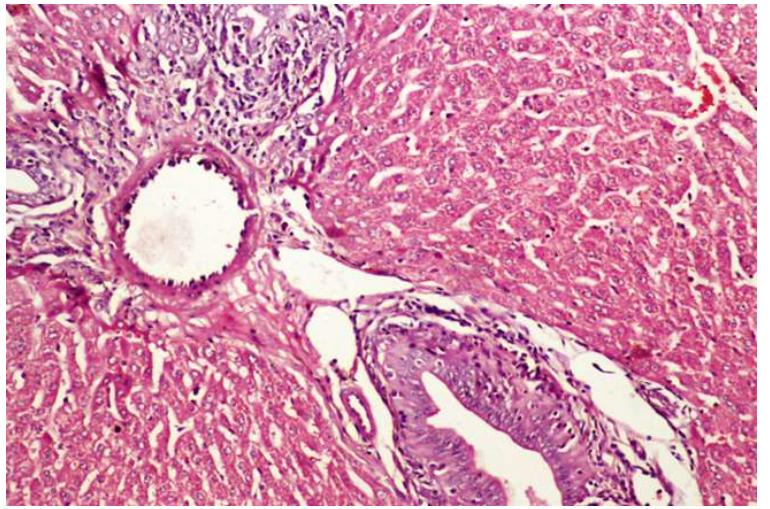

Figure 5: Photomicrograph of liver showing triaditis (H\&E stain X80)

triaditis. Group C showed mild form of triaditis in all slides. Group D and E manifested severe form of triaditis in all slides. Chi-square test revealed very highly significant difference between groups (Table 3, fig. 5).

\section{DISCUSSION:}

This study investigated the effect of coadministration of toxic dose of atorvastatin and three increasing doses of Raphanus sativus leaf extract on serum bilirubin, liver enzymes and liver histology of local breed of rabbits.
Bilirubin level in serum can increase in hepatic disorders. Atorvastatin is known to increase the levels of bilirubin which is an final product of heme metabolism ${ }^{14,15}$. In the present study the level of total, direct and indirect bilirubin increased with atorvastatin but low doses (100mg/kg.b.w.) of Raphanus sativus leaf extract showed a partial reduction in these levels. With increasing doses of extract, further increase was seen. Doses of $300 \mathrm{mg} / \mathrm{kg}$ of ethanolic extract of Raphanus sativus leaf failed to reverse increases in serum bilirubin against toxicity by $\mathrm{CCl}_{4}$ in rats ${ }^{16}$. 
ALT and AST was normal in hepatocytes. Their levels increase in blood when damage occurs to liver cell membrane representing hepatic injury ${ }^{17}$. Earlier studies with atorvastatin have shown an increase in ALT and $\mathrm{AST}^{14,15,18}$. A similar effect was observed in this study i.e. increased ALT and AST (2-3 times the baseline) showing modest liver injury. In experimental groups addition of Raphanus sativus leaf extract indicated a partial reversal of enzyme levels in the dose of $100 \mathrm{mg} / \mathrm{kg}$ b.w. By increasing doses the levels of both AST and ALT showed a further increase as compared to atorvastatin alone used in group B. Regarding the hepatoprotective activity of ethanolic extract of Raphanus sativus leaf in a dose of $300 \mathrm{mg} / \mathrm{kg}$ against $\mathrm{CCl}_{4}$-induced hepatotoxicity in rats showed a partial protective effect ${ }^{16}$. Another study showed a significant increase in AST and ALT level when Raphanus sativus leaf extract was given alone in a dose of $500 \mathrm{mg} / \mathrm{kg}$ in rats ${ }^{19}$. As discussed above histamine may be responsible for these effects as histamine in a dose of $100 \mu \mathrm{g} / \mathrm{kg}$ lead to an increase in levels of ALT and $\mathrm{AST}^{20}$.

Alkaline phosphatase placed among group of hydrolase enzymes is present in almost all body cells including RBCs and removes phosphates from them ${ }^{21}$. Increase in alkaline phosphatase represents cholestasis. Cholestasis symbolizes a continuing acute or chronic process involving intrahepatic or extrahepatic biliary tree. It may include a defective synthesis, obstruction to outflow or defective bile secretion ${ }^{22}$. Atorvastatin in more than $10 \mathrm{mg}$ daily dose leads to an insignificant increase in alkaline phosphatase ${ }^{14}$. In present study 1.5 times increase in alkaline phosphatase level was observed after treatment with high dose atorvastatin. A partial fall in the level of alkaline phosphatase was seen when treated with $100 \mathrm{mg} / \mathrm{kg}$. b. w. of Raphanus sativus as compared to group B but still higher than normal control group A which is in accordance with the study by Syed ${ }^{16}$. Surprisingly the increase was maximal with $200 \mathrm{mg}$ dose of Raphanus sativus (even more than when given atorvastatin alone in group B) while there was less increase with dose of $400 \mathrm{mg}$. This may be explained due to higher intensity of degeneration in group D as observed histologically.

Various studies which have shown a protective effect of Raphanus sativus leaf extract are in lower doses and shorter period of time where $300 \mathrm{mg} / \mathrm{kg}$ dose was given for only seven days against $\mathrm{CCl}_{4}{ }^{16}$. Another example is of use of crude powder of Raphanus sativus in $2 \mathrm{gm}$ and $4 \mathrm{gm}$ dose used only on $46^{\text {th }}$ and $47^{\text {th }}$ day ${ }^{23}$. This may explain the hepatoprotective effect in low doses but an increase in hepatotoxicity was seen with higher doses and long term use.

\section{CONCLUSION:}

The administration of $20 \mathrm{mg} / \mathrm{kg}$ toxic doses of atorvastatin induced hepatotoxicity, manifested as increase in serum levels of ALT, AST, Alkaline Phosphatase and serum
Bilirubin. Low dose of Raphanus sativus leaf extract showed a partial hepatoprotective effect and with high doses an increase in hepatotoxicity was seen. Thus the general concept that Raphanus sativus is hepatoprotective in any dose needs to be reviewed.

\section{ACKNOWLEDGEMENT:}

Thanks to staff of animal house and pathology laboratory for their cooperation.

\section{REFERENCES:}

1. Grigoryan N, Aleksanyan A, Nanagulyan S. Fungal diseases of medicinal plants in arid woodlands of Armenia. Chem Biol. 2015;2:31-3.

2. Abera B. Medicinal plants used in traditional medicine by Oromo people, Ghimbi District, Southwest Ethiopia. Journal of Ethnobiology and Ethnomedicine. 2014;10(1):40.

3. Qadir MI, Ahmad Z. Advances in hepatoprotective medicinal plants research. Bangladesh Journal of Pharmacology. 2017;12(3):229-42, Jul 4, 2017.

4. Sreshta B, Babu SR. Hepatoprotective effect of Poly herbal formulation containing indigenous medicinal plants against various hepatotoxic agents in rats. Asian Journal of Pharmacy and Pharmacology. 2018;4(2):232-7.

5. Udom GJ, Yemitan OK, Umoh EE, Mbagwu H, Ukpe EE, Thomas PS. Hepatoprotective Properties of Ethanol Seed Extract of Citrus paradisi Macfad (Grape Fruit) Against Paracetamol-Induced Hepatotoxicity in Wistar Rats. Journal of Herbal Drugs (An International Journal on Medicinal Herbs). 2018;8(4):219-27.

6. Sabir SM, Rocha JBT, Boligon AA, Athayde ML. Hepatoprotective activity and phenolic profile of Zanthoxylum alatum Roxb. fruit extract. Pakistan journal of pharmaceutical sciences. 2017;30(5).

7. Dinesh K, Sivakumar V, Selvapriya B, Deepika E, Sadiq AM. Evaluation of hepatoprotective polyherbal formulations contains some Indian medicinal plants. Journal of Pharmacognosy and Phytochemistry. 2014;3(4).

8. Bersot TP. Drug therapy for hypercholesterolemia and dyslipidemia. Goodman and Gilman's, The Pharmacological Basis of Therapeutics McGraw-Hill. 2011:877-908.

9. Dureja H, Kaushik D, Kumar V. Developments in nutraceuticals. Indian journal of pharmacology. 2003;35(6):363-72.

10. Mohammed GJ, Hameed IH. Pharmacological Activities: Hepatoprotective, Cardio Protective, Anti-cancer and AntiMicrobial Activity of (Raphanus Raphanistrum Subsp. Sativus): A review. Indian Journal of Public Health. 2018;9(3):213.

11. Gilani AH, Ghayur MN. Pharmacological basis for the gut stimulatory activity of Raphanus sativus leaves. Journal of ethnopharmacology. 2004;95(2-3):169-72.

12. Kim WK, Kim JH, Jeong DH, Chun YH, Kim SH, Cho KJ, et al. Radish (Raphanus sativus L. leaf) ethanol extract inhibits protein and mRNA expression of ErbB2 and ErbB3 in MDAMB-231 human breast cancer cells. Nutrition research and practice. 2011;5(4):288-93.

13. Suvarna S, Layton C. Bancroft's theory and practice of histological techniques, expert consult: online and print, 7: Bancroft's theory and practice of histological techniques. Churchill Livingstone Elsevier. 2013. 
14. Flora F. Treated Patients Biochemical Studies on the Hepatotoxicity of Atorvastatin. International Journal of Biochemistry and Biophysics. 2014;2(4):41-62.

15. Taleb MH, Almasri IM, Siam NI, Najim AA, Ahmed AI. The effect of atorvastatin on liver function among patients with coronary heart disease in Gaza Strip. Pharmacology \& Pharmacy. 2014;5(08):781.

16. Syed SN, Rizvi W, Kumar A, Khan AA, Moin S, Ahsan A. In Vitro Antioxidant and In Vivo Hepatoprotective Activity of Leave Extract of Raphanus sativus in Rats Using CCL 4 Model. African Journal of Traditional, Complementary and Alternative Medicines. 2014;11(3):102-6.

17. van Beek JH, de Moor MH, de Geus EJ, Lubke GH, Vink JM, Willemsen G, et al. The genetic architecture of liver enzyme levels: GGT, ALT and AST. Behavior genetics. 2013;43(4):329-39.

18. Heeba GH, Abd-Elghany MI. Effect of combined administration of ginger (Zingiber officinale Roscoe) and atorvastatin on the liver of rats. Phytomedicine. 2010;17(14):1076-81.
19. Shah M, Shahu G, Tamrakar AK, Malshetthy S, Janadri S, Swamy S. Cardiotoxic Activity of Leaves Extract of Raphanus sativus Linn. in Adult Male Albino Rats. International Journal of Pharmaceutical and Phytopharmacological Research. 2017;4(1):66-9.

20. Tripathi T, Shahid M, Khan HM, Khan RA, Siddiqui M, Mahdi AA. The Influence of histamine H1-receptor on liver functions in immunized rabbits. Saudi journal of biological sciences. 2011;18(4):411-8.

21. Ahmadpour-Kacho M, Pasha YZ, Haghshenas M, Rad ZA, Firouzjahi A, Bijani A, et al. Cord blood alkaline phosphatase as an indicator of neonatal jaundice. Iranian journal of pediatrics. 2015;25(5).

22. Siddique A, Kowdley KV. Approach to a patient with elevated serum alkaline phosphatase. Clinics in liver disease. 2012;16(2):199-229.

23. Anwar R, Ahmad M. Studies of Raphanus sativus as Hepato Protective agent. J Med Sci. 2006;6(4):662-5. 